\title{
Repeated social defeat promotes persistent inflammatory changes in splenic myeloid cells; decreased expression of $\beta$-arrestin-2 (ARRB2) and increased expression of interleukin- 6 (IL-6)
}

Dhaksshaginy Rajalingam ${ }^{1 *+} \mathbb{0}$, Ingeborg Nymoen ${ }^{2+}$, Daniel Pitz Jacobsen², Mina Baarnes Eriksen², Erik Dissen ${ }^{3}$, Morten Birkeland Nielsen ${ }^{1,2}$, Ståle Valvatne Einarsen ${ }^{1}$ and Johannes Gjerstad ${ }^{1,2}$

\begin{abstract}
Background: Previous studies suggest that persistent exposure to social stress in mammals may be associated with multiple physiological effects. Here, we examine the effects of social stress in rats, i.e. repeated social defeat, on behavior, hypothalamic-pituitary-adrenal (HPA)-axis and immune system.

Methods: A resident-intruder paradigm, where an intruder rat was exposed to social stress by a dominant resident rat for 1 hour each day for 7 consecutive days was used. The day after the last stress exposure in the paradigm the data were analyzed. Variation in social interaction was observed manually, whereas locomotion was analyzed off-line by a purpose-made software. Gene expression in the pituitary gland, adrenal gland and myeloid cells isolated from the spleen was measured by qPCR.

Results: The exposure to social stress induced decreased weight gain and increased locomotion. An increased nuclear receptor subfamily group C number 1 (NR3C1) expression in the pituitary gland was also shown. In myeloid cells harvested from the spleen, we observed decreased expression of the $\beta_{2}$-adrenergic receptor (ADRB2) and $\beta$-arrestin-2 (ARRB2), but increased expression of interleukin-6 (IL-6). Subsequent analyses in the same cells showed that ARRB2 was negatively correlated with IL-6 following the stress exposure.

Conclusion: Our results show that that the experience of social stress in the form of repeated social defeat in rats is a potent stressor that in myeloid cells in the spleen promotes persistent inflammatory changes. Future research is needed to examine whether similar inflammatory changes also can explain the impact of social stress, such as bullying and harassment, among humans.
\end{abstract}

Keywords: Social stressors, Repeated social defeat, Bullying, ADRB2, ARRB2, IL-6

*Correspondence: Dhaksshaginy.Rajalingam@uib.no

${ }^{\dagger}$ Dhaksshaginy Rajalingam and Ingeborg Nymoen contributed equally to this work

1 Department of Psychosocial Science, University of Bergen, Bergen,

Norway

Full list of author information is available at the end of the article

\section{Background}

Previous studies show that environmental stressors in mammals induce increased activity of the sympathetic nervous system (SNS) and the hypothalamic-pituitaryadrenal (HPA)-axis [1-3]. Activation of these systems may be associated with altered behavior [4], hormonal signaling [5] as well as changes in the immune system, for review see [6]. Environmental stressors may promote myelopoiesis in the bone marrow [7], glucocorticoid

(c) The Author(s) 2020. This article is licensed under a Creative Commons Attribution 4.0 International License, which permits use, sharing, adaptation, distribution and reproduction in any medium or format, as long as you give appropriate credit to the original author(s) and the source, provide a link to the Creative Commons licence, and indicate if changes were made. The images or other third party material in this article are included in the article's Creative Commons licence, unless indicated otherwise in a credit line to the material. If material is not included in the article's Creative Commons licence and your intended use is not permitted by statutory regulation or exceeds the permitted use, you will need to obtain permission directly from the copyright holder. To view a copy of this licence, visit http://creativeco mmons.org/licenses/by/4.0/. The Creative Commons Public Domain Dedication waiver (http://creativecommons.org/publicdomain/ zero/1.0/) applies to the data made available in this article, unless otherwise stated in a credit line to the data. 
(GC) resistance in the brain and the spleen [8], increased circulatory levels of cytokines [9] and altered inflammatory profile in the brain [10].

Recent data demonstrate that exposure to repeated social defeat-through the resident-intruder paradigm in rats or bullying in humans-is a strong environmental stressor [11]. Previous observations show that environmental stressors may induce neuronal activation of the reticular formation in the brain stem including locus coeruleus (LC) [1], which in turn affects efferent sympathetic nerve fibers that innervate the adrenal gland and spleen $[12,13]$. In the adrenal medulla, this innervation results in epinephrine (E) release from chromaffin cells into the circulation $[14,15]$. In addition, exposure to environmental stressors leads to activation of the paraventricular nucleus $(\mathrm{PVN})$ of the hypothalamus [1]. This stimulates the HPA-axis through corticotropin releasing hormone $(\mathrm{CRH})[16]$ that promotes secretion of corticosteroids (CORTs) from the adrenal cortex [17].

Regarding the autonomic influence on the thymus, spleen, lymph nodes and bone marrow, norepinephrine (NE) signaling by efferent sympathetic nerve fibers plays a crucial role [18]. Stimulation of adrenergic receptors on immune cells causes changes in differentiation, inflammatory profile and migration capacity $[19,20]$. For instance, increased sympathetic signaling may facilitate the induction of genes involved in myeloid lineage effector functions, signal transduction and transcription control [7]. Earlier observations suggest that stressinduced inflammation and myelopoiesis may be linked to increased activity of transcription factors such as nuclear factor kappa B (NF-kB) $[7,9]$.

Evidence exists that activation of the SNS and HPAaxis may be involved in the regulation of leukocyte trafficking [21, 22]. Leukocyte counts have also revealed increased cell numbers in bone marrow, peripheral blood and spleen following repeated social defeat in mice [23]. These observations are consistent with stress-induced changes in splenic neutrophil and macrophage numbers. Moreover, stress may cause leukocyte recruitment from the bone marrow to the spleen [23]. Increased levels of granulocyte-monocyte colony-stimulating factor (GM-CSF) in circulating monocytes may be a part of the underlying mechanism [7]. Further observations suggest that repeated social defeat may lead to increased release of monocyte chemoattractant protein-1 (MCP-1) from microglia cells [24], which induces monocyte recruitment from the spleen to the capillaries in the brain [10].

It has been proposed that environmental stressors, through activation of $\beta 2$-adrenergic receptors (ADRB2s), may lead to inflammatory changes of splenic immune cells $[7,25,26]$. In addition, earlier observations suggest that persistent activation of ADRB2s in murine macrophages increases mRNA and protein levels of proinflammatory cytokines such as interleukin-6 (IL-6) and interleukin-1 $\beta$ (IL-1 $\beta$ ) [27]. Moreover, evidence exists that $\beta 2$-adrenergic signaling also involves $\beta$-arrestin 2 (ARRB2), a protein known to inhibit NF-kB nuclear translocation by stabilizing cytoplasmic $\mathrm{I} \kappa \mathrm{B} \alpha$ activity through ADRB2 activation [28, 29]. However, whether or not ADRB2 and ARRB2 may be associated with the expression of cytokines such as IL-6 during social stress has not been clarified. The aim of the present study was to examine the effect of social defeat on the neuroimmune interface.

\section{Methods \\ Animals}

As described below, a resident-intruder paradigm, where Sprague-Dawley intruder rats were exposed to social stress by dominant Long Evans resident rats; $1 \mathrm{~h}$ each day (between 09:00 and 13:00) for 7 consecutive days, was used to study stress-induced changes in the HPA-axis and the immune system. Each of the ten male Long Evans rats $(500-550 \mathrm{~g})$ was housed with a female Long Evans rat (200-250 g) in a $0.56 \mathrm{~m}^{2}$ cage. The ten male SpragueDawley rats (300-400 g) used as intruders were housed in pairs, as were the ten male Sprague-Dawley rats (300$400 \mathrm{~g}$ ) used as controls. The different strains-Long Evans rats from Envigo; USA and Sprague-Dawley rats from Janvier Labs; France-were kept in separate rooms. All rats were acclimatized to a 12:12 h light:dark cycle, ventilation rate of $15 \times$ air per hour, $21-22{ }^{\circ} \mathrm{C}$ and $45-55 \%$ humidity. At all times, the rats had ad libitum access to food and water. Bedding was changed once a week. All animal procedures were approved by the Norwegian Food Safety Authority and performed in conformity with laws and regulations controlling experiments and procedures on live animals in Norway.

\section{Screening}

To ensure dominant behavior of Long Evan males i.e., the resident rats in the paradigm, a screening was performed prior to the stress-conditioning week. Top ten aggressive rats were chosen based on the highest incidences of attacks over a period of $10 \mathrm{~min}$.

\section{Resident-intruder paradigm}

First, the female rat was temporarily removed from the resident cage 1 hour before the stress conditioning. Next, the stress conditioning was performed by introducing the intruder animal into the resident cage. The male resident and intruder rat were separated upon three episodes of social defeat (submissive supine posture, freeze or flight), or after $10 \mathrm{~min}$ of interaction by a perforated plastic wall, allowing the intruder rat to still see, smell and hear the 
resident rat. Finally, after $60 \mathrm{~min}$ in the resident cage, the intruder rat was returned to its home cage, and the female rat was returned to the resident cage. The conditioning procedure described above was repeated for 7 days. To prevent habituation to the dominance establishment with the resident rat, the intruder animals were introduced to a new resident animal every day. The animals randomized to control followed the same procedure except that they visited a foreign cage without a resident rat.

\section{Social interaction test}

A modified version of the social interaction test was used to assess the social interaction behavior of the SpragueDawley rats (i.e., the test rats) following 1week of stress or control conditioning [30]. More specifically, the social interaction test was conducted 1 day after the last episode of defeat. The test arena was a purpose made box $\left(0.56 \mathrm{~m}^{2}\right)$ divided into three compartments by two gated plastic walls and a small wire-like container in each flanking compartment. The test rats were allowed to habituate in the center compartment for 4 minutes (Additional file 1: Fig. S1a) before a novel rat of the same strain was placed into one of the small wire-like containers (Additional file 1: Fig. S1b). The subsequent opening of the gates allowed the test rat to move freely between the compartments for 6 minutes (Additional file 1: Fig. S1c). Movement and behavior of the test animals were recorded by a camera placed in a rack above the box. Thus, changes in behavior were examined after the experiments, including the time spent in each chamber and the time spent in direct social interaction with the novel rat. The novel rats were habituated to the wire-like container prior to the social interaction test, but did not take part in the resident-intruder paradigm.

\section{Video analysis}

Recorded videotapes of rats moving in the three-chamber box were analyzed using a purpose-made software program, which was programmed and developed in C. The time spent in each of the three chambers and locomotion of rats (10 s intervals) were scored by the software.

\section{Anesthesia and blood sampling}

Following the social interaction test and one hour rest in their home cage, on day 8, the intruder Sprague-Dawley and control rats were sedated with $5 \%$ isoflurane in air in a gas box prior to being moved to a $3 \%$ isoflurane anesthetic gas mask. Absence of withdrawal reflexes was considered sufficient anesthesia for surgery.

The animal was fixated in a dorsal recumbence position and a v-cut through the skin and abdominal wall was made. The heart was exposed by opening the thoracic cage, cutting through the diaphragm. A $10 \mathrm{~mL}$ syringe with a $1.2 \mathrm{~mm}$ cannula coated with $1.8 \mathrm{mg} / \mathrm{mL}$ EDTA (Sigma Life Science; Switzerland), was inserted into the left ventricle (cardiac puncture). Blood samples of $2 \mathrm{ml}$ were drawn from the exposed and control Sprague-Dawley rats. In accordance with the procedure previously described, $500 \mu \mathrm{L}$ of the blood was immediately placed on liquid nitrogen for $\mathrm{NE}$ and CORT concentration measurements performed (Additional file 1: Fig. S2) [31].

\section{Tissue harvesting}

All Sprague-Dawley rats were euthanized by dislocation of the neck under isoflurane anesthesia. The pituitary gland and adrenal glands were harvested, frozen on liquid nitrogen and later stored in a $-80{ }^{\circ} \mathrm{C}$ freezer.

\section{Enrichment of splenic myeloid cells}

The spleen was mechanically disrupted with scissors, and pieces of spleen tissue were passed multiple times through a $10 \mathrm{~mL}$ syringe and filtered through a $70 \mu \mathrm{M}$ cell strainer in order to get a single cell suspension. Mononuclear cells were retrieved by density centrifugation. The suspension was diluted with PBS (GE Healthcare Lifesciences; USA), loaded on top of a $15 \mathrm{~mL}$ Lymphoprep ${ }^{\mathrm{TM}}$ medium (STEMCELL technologies; Norway) and centrifugated $\left(400 \mathrm{xg}\right.$ for $30 \mathrm{~min}$ at $4{ }^{\circ} \mathrm{C}$ ). The layer of mononuclear cells was carefully aspirated, diluted in PBS supplemented with $2 \% \mathrm{FBS}$, washed by centrifugation (300xg, $\left.10 \mathrm{~min}, 4{ }^{\circ} \mathrm{C}\right)$ and resuspended in PBS (2\% FBS). Myeloid cells were purified from the spleen mononuclear fraction by immunomagnetic bead separation. To avoid unspecific monoclonal antibody ( $\mathrm{mAb}$ ) binding, the Fc receptors were pre-blocked by incubating the cells in PBS with $10 \%$ rat serum for $15 \mathrm{~min}$ at $4{ }^{\circ} \mathrm{C}$. Subsequently, cells were incubated with a biotinylated mouse $\mathrm{mAb}$ (OX41) specific for rat CD172a (SIRP- $\alpha$, expressed on the surface of all myeloid cells) at $2 \mu \mathrm{g} / \mathrm{mL}$ in PBS (10\% rat serum) for $15 \mathrm{~min}$ at $4{ }^{\circ} \mathrm{C}$ and washed three times in PBS (2\% FBS, $10 \mathrm{mM} \mathrm{NaN}_{3}$ ) before incubation with streptavidine-coated magnetic microbeads (MACS, Miltenyi Biotec; Germany) resuspended in PBS supplemented with $2 \mathrm{mM}$ EDTA and $0.5 \% \mathrm{BSA}$ for $30 \mathrm{~min}$ at $4{ }^{\circ} \mathrm{C}$, using $40 \mu \mathrm{L}$ of beads per $4 \times 10^{7}$ cells. The cells were then run through MACS LS columns in the magnetic field of a quadroMACS ${ }^{\mathrm{TM}}$ separator (Miltenyi Biotec; Germany) to separate bead-captured cells from unstained, non-myeloid cells according to manufacturer instructions.

\section{Flow cytometry}

Flow cytometry was used to verify the enrichment of CD172 positive cells and the nature of contaminating non-myeloid cells. Two separate mixes of fluorochromeconjugated mAbs for test and isotype controls were used, 
diluted in PBS (2\% FBS, $10 \mathrm{mM} \mathrm{NaN}_{3}$ ) (Additional file 1: Table S1). Staining with isotype control antibodies was included to evaluate unspecific mAb binding capacity to splenic cell subsets.

A small fraction of the cell sample i.e., $3 \times 10^{5}$, was used for flow cytometry analysis and incubated with 50 $\mu \mathrm{L} \mathrm{mAb}$ test or isotype mix $(2 \mu \mathrm{g} / \mathrm{mL})$ in PBS $(2 \% \mathrm{FBS}$, $10 \mathrm{mM} \mathrm{NaN}_{3}$ ) for $30 \mathrm{~min}$ on ice. After staining with primary antibody mixes, the cells were washed three times by centrifugation $\left(300 \mathrm{xg}, 2 \mathrm{~min}, 4{ }^{\circ} \mathrm{C}\right)$, resuspended in PBS (2\% FBS, $10 \mathrm{mM} \mathrm{NaN}_{3}$ ) and incubated with Streptavidin-Alexa Fluor 647 conjugated for detection of OX41biotin or IgG1-biotin binding, respectively. Cells were washed and analyzed on a CytoFlex flow cytometry (Beckman Coulter Life Sciences, USA) using CytExpert software.

\section{RNA isolation and CDNA synthesis}

The allprep DNA/RNA/miRNA Universal Kit (Qiagen; Germany) was used to isolate total RNA from the frozen pituitary, adrenal and enriched myeloid cells. Total RNA was extracted by homogenizing the frozen tissue with magnetic beads in a bead beater. The lysate was then used for RNA isolation following the manufacturer's protocol. Synthesis of cDNA from these tissues was carried out using the qSCript cDNA synthesis kit (Quanta Biosciences Inc.; USA).

\section{Gene expression analyses}

RNA quantification of the different genes was achieved by a two-step real-time reverse transcription qPCR (RTqPCR). Primer sequences (fwd,rev) were from Sigma Life Sciences, Switzerland: POMC (5'AACGCCATCAAG AAC3' and 5'AAGGTTTTATTTCCTAACTACAC3'); NR3C1 (5'CAGAGAATGTCTCTACCCTG3' and 5'CTT AGGAACTGAGGAGAGAAG3'); MC2R (5'AGAAAC
TGGATCCTTCCG3 ${ }^{\prime}$ and 5'TGGTGTGTTCATACG AATTG3'); $\beta$-actin (5'CTAAGGCCAACCGTGAAA

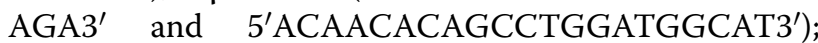
IL-6 (5'TGCCCTTCAGGAACA3' and 5'AAGGCAGTG GCTGTC3'); ADRB2 (5'AAAGAGAGAGAGAGAGAC T3' and 5'ACAACACTTCAGACAGAAAC3'); HPRT (5'ACTGGTAAAACAATGCAGGAC ${ }^{\prime}$ and ${ }^{\prime}$ 'CCTGAA GTGCTCATTATAGTC $\left.3^{\prime}\right)$; PtPrc (5'GCTATAAAAAGA CCCCTTCAG3' and 5'CATAGGCAAATAGAGACA CTG3'); ARRB2 (5'GCAGCCAGGACCAGAGGACA3' and $5^{\prime}$ CCACGCTTCTCTCGGTTGTC $3^{\prime}$ ). PCR was run on Quantstudio 5 (Thermofisher Scientific; Norway) and analyzed using Quantstudio ${ }^{\mathrm{TM}}$ Design and Analysis Software.

\section{Statistics}

The data were shown by representative examples and mean \pm standard error of the mean. Statistical analyses were conducted with Sigmaplot 14.0 and the level of significance was set to $\mathrm{p}<0.05$. Shapiro-Wilk test was run to assess normality. Differences in body weight, social interaction, locomotion, gene expression levels and differences in percentage of myeloid cells between exposed group and control group were analyzed using Student's $t$ test.

\section{Results \\ Behavior}

The resident-intruder paradigm changed the behavior of the intruder rats in the residential cage (Fig. 1). For each day passing, the number of rats showing subordinate defeat behavior increased. After 6 days of stress conditioning all intruder rats showed a clear social defeat within the 10-min frame (Fig. 2a).

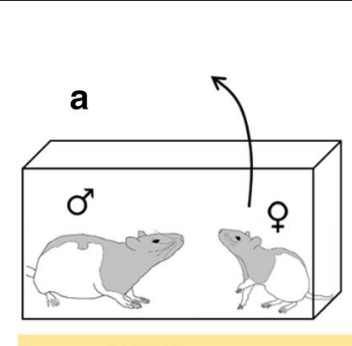

$-60 \mathrm{~min}$

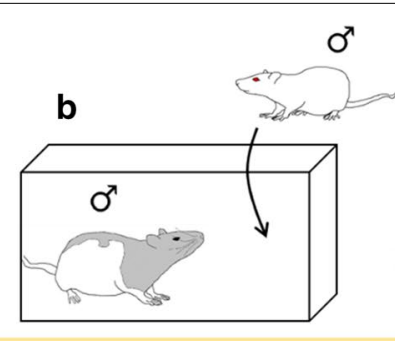

$0-10 \mathrm{~min}$

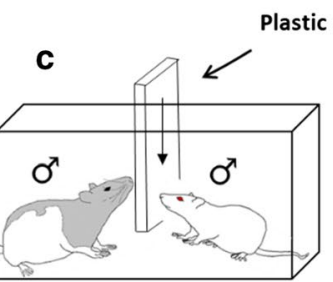

After fight/defeat

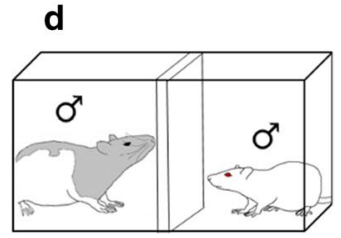

$50-60 \mathrm{~min}$

Fig. 1 Resident-intruder paradigm. The set-up used to induce defeat stress in the intruder Sprague-Dawley rats (white) in the cage of the resident male Long Evans rat (black-hooded). a The Long Evans female was removed 60 min prior to the experiment. b An intruder Sprague-Dawley rat was placed in the home cage of a resident male Long Evans rat. c Upon three episodes of social defeat (submissive supine posture, freeze or flight), or after 10 min of interaction, a plexiglas wall was used to separate the resident and intruder rats. $\mathbf{d}$ Sensory interaction in the divided cage was allowed for the remaining time of the hour. Both the male Sprague-Dawley and female Long Evans rats were returned to their home cage after the conditioning. (lllustrated by Nymoen, I.) 

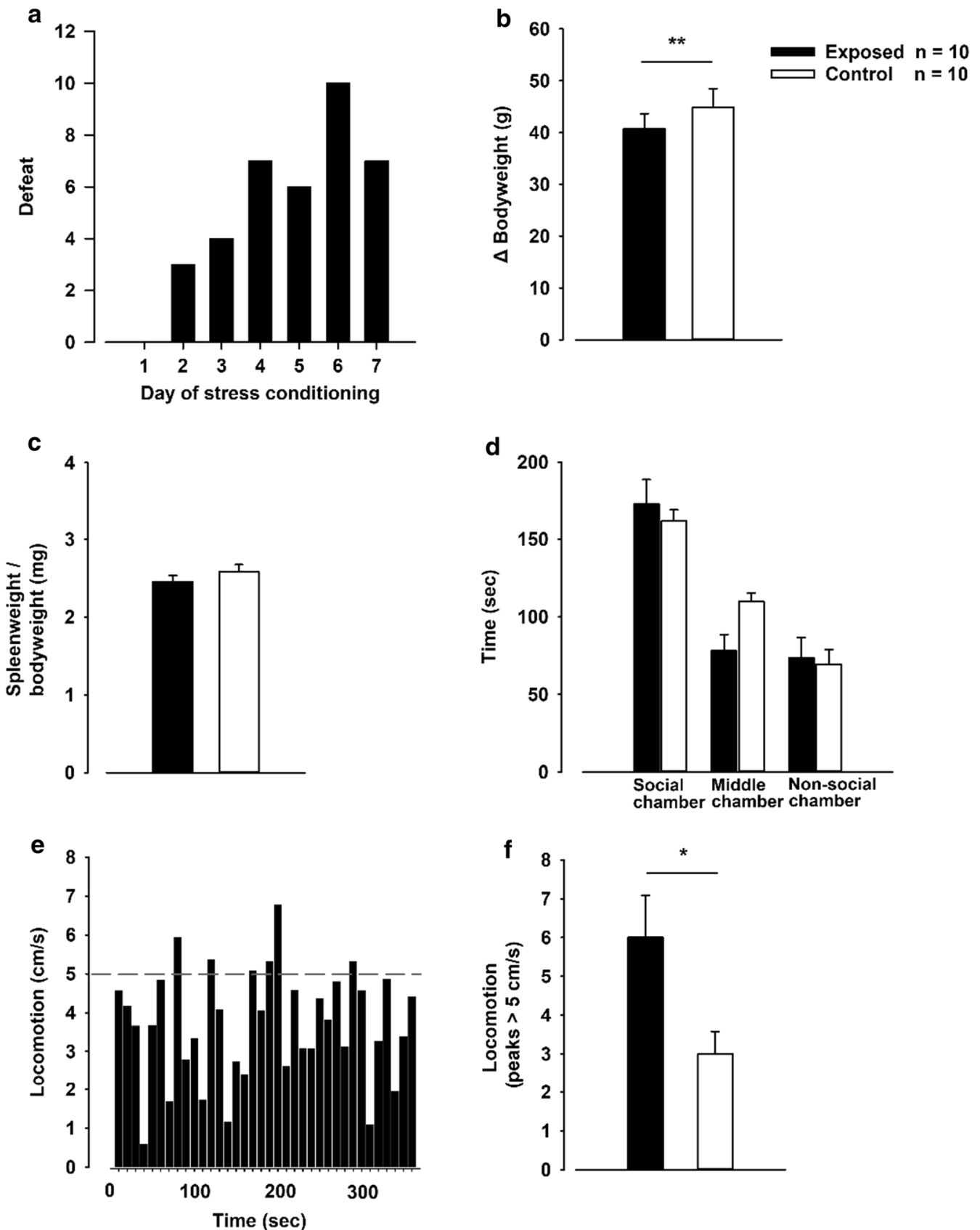

Fig. 2 Behavior, weight gain and locomotion. a Number of defeated stress-exposed rats (intruder rats) during conditioning at day 1-7. b Bodyweight at day seven in stress-exposed rats versus control rats (relative to baseline), $p=0.007$. c Organ-to-bodyweight ratio of the spleen in stress-exposed rats versus control rats. $\mathbf{d}$ Social interaction test; time spent in the three different chambers, stress-exposed rats versus control rats. e Example of locomotion in the three different chambers ( $10 \mathrm{~s}$ intervals). f Peak locomotion $>(5 \mathrm{~cm} / \mathrm{s})$ stress-exposed rats versus control rats, $p=0.029 .{ }^{*} p<0.05,{ }^{* *} p<0.01$, Students t-test

The exposed rats gained less weight during the conditioning week, compared to controls (Fig. 2b). However, we did not observe any increase of spleen weight-to-bodyweight ratio (Fig. 2c), and thus there was no evidence of splenomegaly following stress exposure.
Following the conditioning week, all exposed and control animals went through a social interaction test. No difference was observed between the two groups, evaluated by time spent in the three different chambers (Fig. 2d). Locomotion $(\mathrm{cm} / \mathrm{s})$ of the rats in $10 \mathrm{~s}$ intervals 
was measured by a computer. The stress exposed rats had significantly higher locomotion compared to control rats (Fig. 2e, f).

\section{HPA-axis gene expression and NE/CORT in plasma}

The stress exposure did not result in any clear changes of pro-opiomelanocortin (POMC) (Fig. 3a), but showed a significant increase in the expression of NR3C1 in the pituitary gland (Fig. 3b). The exposure did not alter adrenal gland expression of MC2R (ACTH receptor) or NR3C1 (Fig. 3c, d) nor the NE or CORT levels in plasma (Additional file 1: Fig. S2a, b).

\section{Enrichment of splenic myeloid cells}

Flow cytometry analysis of the final cell suspension from the enrichment procedure was performed to elucidate the amount of myeloid cells compared to the amount of contaminating cells (Fig. 4a-f, Additional file 1: Fig.S3). The estimated SIRP- $\alpha$ positive fraction was $81.9 \% \pm 1.73$ in the exposed group and $86.6 \% \pm 1.12$ in the control group. The predominant contaminating cell type was CD45RABC positive cells (most likely B cells). We observed $12.1 \% \pm 1.28 \mathrm{CD} 45 \mathrm{RABC}$ positive cells in the exposed group and $8.82 \% \pm 0.77 \mathrm{CD} 45 \mathrm{RABC}$ positive cells in the control group (Fig. 4g).

\section{Gene expression in splenic myeloid cells}

The ADRB2 and ARRB2 were both significantly downregulated following 1 week of stress exposure (Fig. 5a, b). In addition, our results showed an increased expression of IL- 6 in exposed animals compared to controls and that the IL-6 levels were associated with ARRB2 levels in myeloid cells (Fig. 5c, d). The NR3C1 expression levels revealed no difference in the cell population studied (Additional file 1: Fig. S4).

\section{Discussion}

In the present study, we addressed stress-induced changes in behavior, HPA-axis and immune system. In addition to increased locomotion and reduced weight
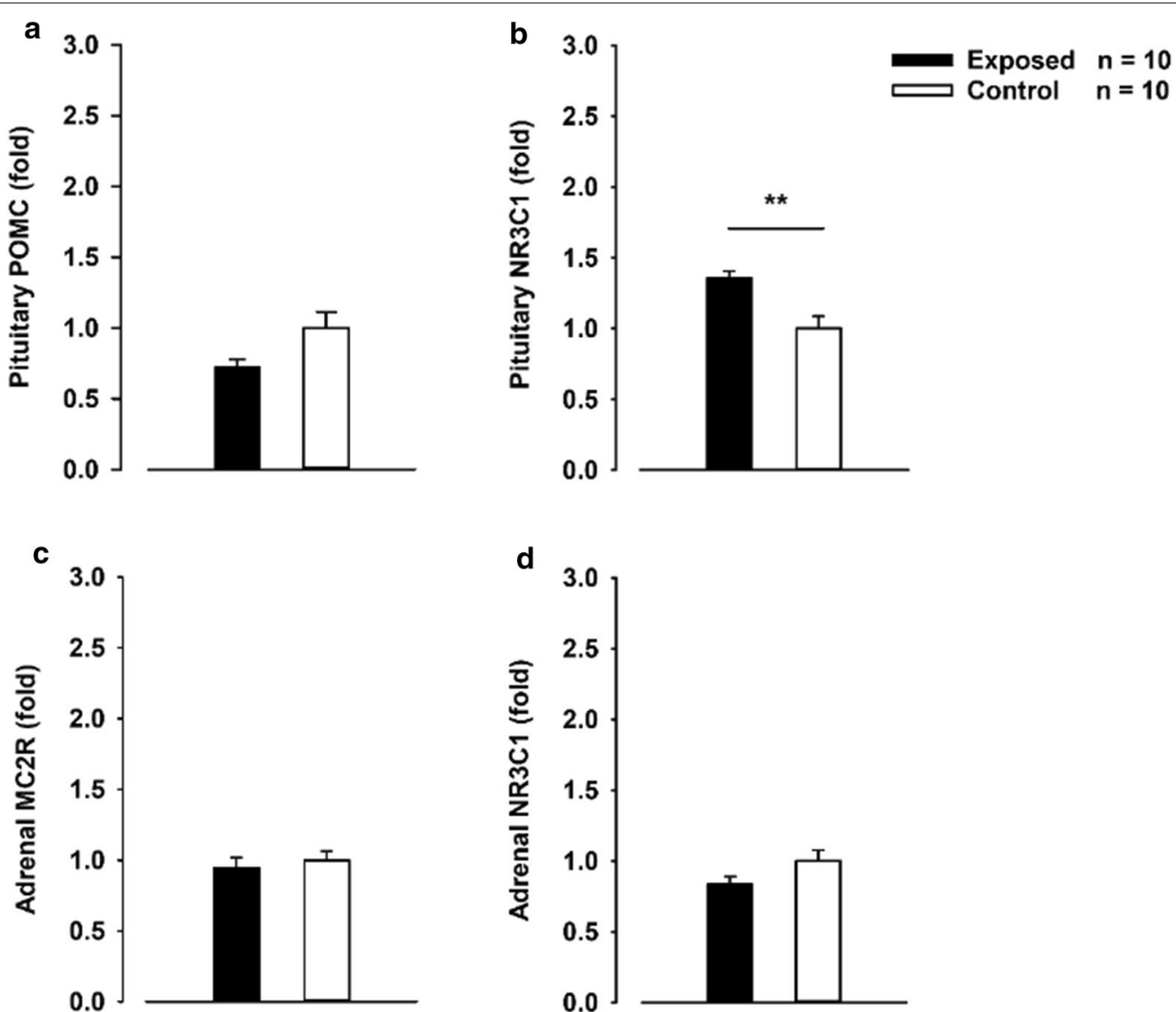

Fig. 3 The pituitary- and adrenal- gland. a, b Fold expression of adrenocorticotropic hormone (ACTH) precursor POMC, and glucocorticoid receptor ( $\mathrm{Nr} 3 \mathrm{C} 1$ ) in the pituitary gland of stress-exposed rats versus control rats, $\mathrm{p}=0.003$. $\mathbf{c}, \mathbf{d}$ Fold expression of melanocortin type-2 receptor (MC2R) and $\mathrm{Nr} 3 \mathrm{C} 1$ in the left adrenal gland of stress-exposed rats versus control rats. The data were normalized to $\beta$-actin and then to baseline. ${ }^{*} \mathrm{p}<0.05$, ${ }^{* *} p<0.01$, Students t-test 


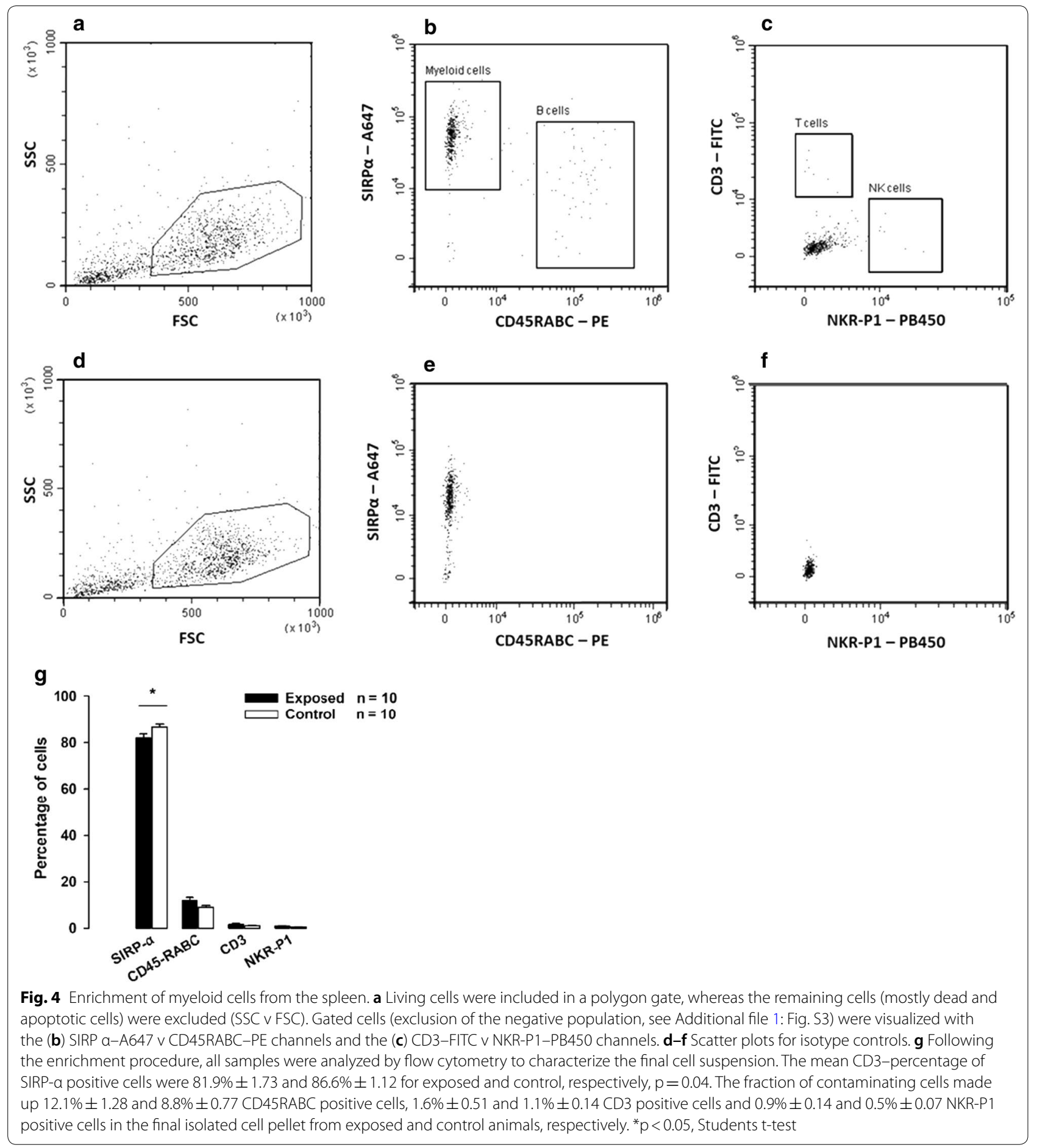

gain, we observed an increased NR3C1 expression in the pituitary gland after 1 week with social stress. The most robust effects of the stress exposure were, however, seen on isolated splenic immune cells. In these myeloid cells, we observed decreased expression of the ADRB2 and ARRB2, but increased expression of IL-6, the day after the last stress exposure in the paradigm. Moreover, stress exposure induced a downregulation of ARRB2 that was negatively correlated with IL-6. Hence, the present data support the idea that reduced expression of ARRB2 may enhance the translocation of the NF- $\mathrm{kB}$ to the nucleus and activate the transcription of IL-6. 

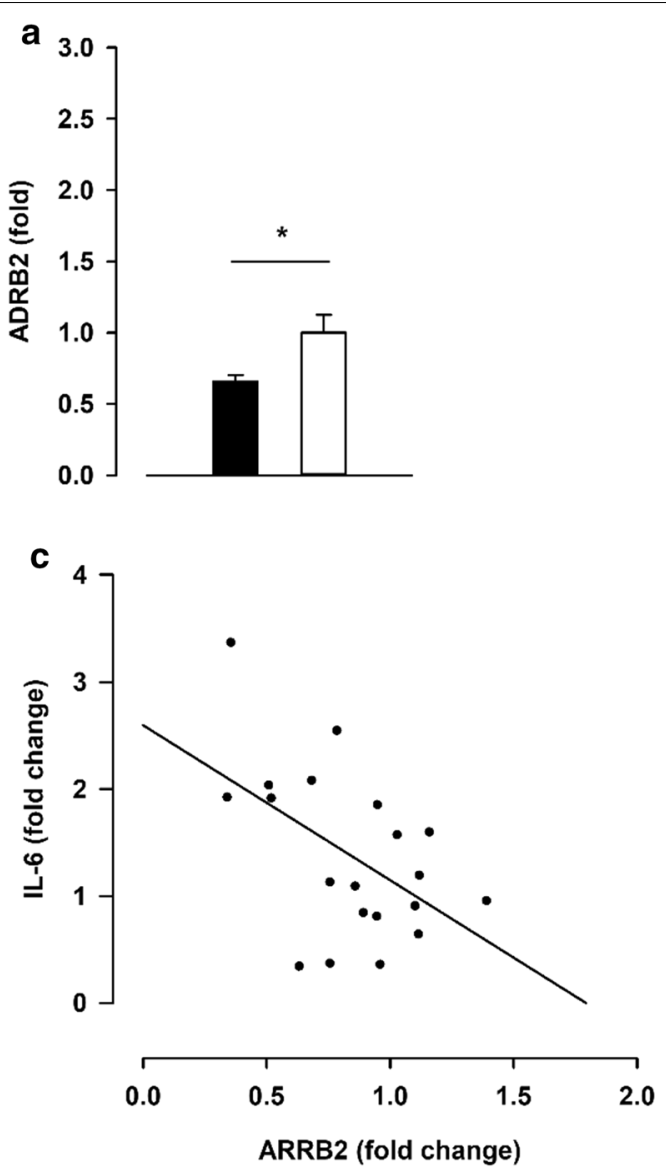

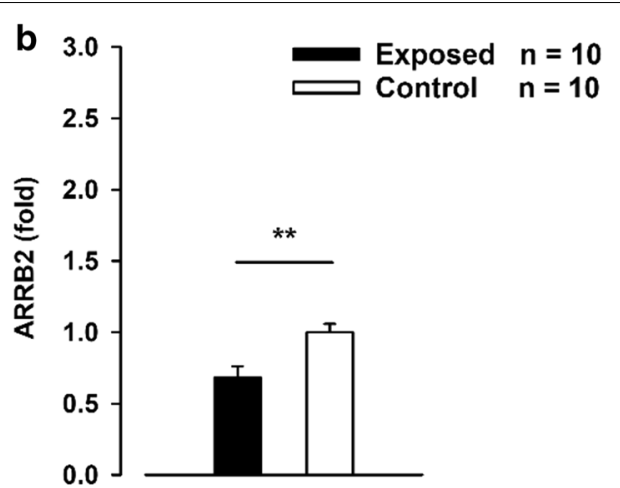

d

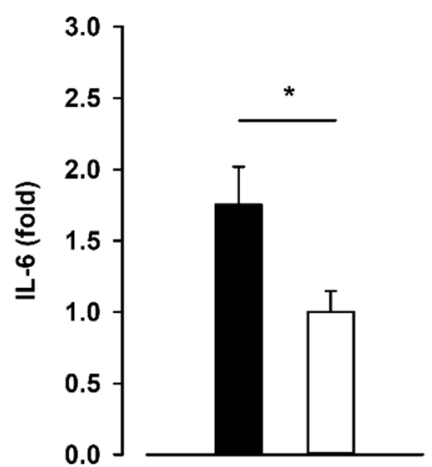

Fig. 5 Myeloid cells from the spleen. a Fold expression of $\beta 2$-adrenergic receptor (ADRB2) in the stress-exposed rats versus control rats, $p=0.02$. $\mathbf{b}$ Fold expression of $\beta$-arrestin 2 (ARRB2) in stress-exposed rats versus control rats, $p=0.007$. $\mathbf{c}$ The relationship between IL- 6 and ARRB2 expression levels, $r=0.509, p=0.022$. d Fold expression of interleukin 6 (IL-6) in the stress-exposed rats versus control rats, $p=0.02$. All data were normalized to the mean of hypoxanthine phosphoribosyltransferase (HPRT) and protein tyrosine phosphatase receptor type C (PTPRC) and then to the baseline. ${ }^{*} p<0.05,{ }^{* *} p<0.01$, Students t-test

Earlier findings in murine models indicate that stressinduced physiological changes, including reduced CORT sensitivity in peripheral macrophages, central microglia activation and anxiety-like behavior during stress exposure, may be cycle-dependent, i.e., increases for each stress episode. Previous data also show a stress-induced reduced preference towards sucrose [32] and IL-6 driven energy expenditure affecting gain of body weight [33]. It is therefore tempting to speculate that the observed submissive behavior may involve depression and lack of appetite, but also learned helplessness behavior [34] and enhanced punishment avoidance [35, 36]. In accordance with earlier observations $[1,4,37]$, we demonstrated a clear stress-induced decrease in weight gain.

Several studies suggest that the resident-intruder paradigm in mice may cause leukocyte egress from the bone marrow, enhanced recruitment of myeloid cells to the spleen, which in turn may be associated with splenomegaly, i.e., increased spleen weight $[21-23,38]$.
However, since the enhanced recruitment of myeloid cells to the spleen have been reported to be more pronounced in wounded animals than in those without any injuries [23], the earlier reported stress-induced splenomegaly could be a result of the immunological changes caused by infections etc. Thus, splenomegaly may be a result of physical injuries (wounds) rather than social stress.

In the present study we used rats, not mice. Therefore, it was possible to avoid bites and wounds. The intruder animals in our study were therefore only exposed to social stress, not confounding factors such as physical injuries that could lead to immunological changes caused by infections. Interestingly, the present resident-intruder paradigm in our study, where we used rats, did not change the spleen volume/weight. Therefore, the present study supports the idea that splenomegaly induced by the resident-intruder paradigm may be explained by infections rather than social stress. 
Exposure to chronic stress may impair neurogenesis in the prefrontal cortex (PFC) and hippocampus, but have the opposite effect in amygdala [39-41]. Moreover, stress may induce amygdala hyperactivity, increase synaptic connectivity in amygdala [42], and stimulate amygdala-dependent fear learning [43]. Thus, when the exposure to stress persists, the brain seems to switch from slow, attentive PFC regulation to more reflexive responses predominantly controlled by the amygdala and related subcortical structures [44, 45]. Social stress, which involves PFC dysregulation and amygdala hyperactivity, could therefore also promote behavioral changes such as rapid movements observed in the present study.

Previous studies suggest a link between stress-induced migration of leukocytes from the bone marrow and splenomegaly [21-23, 38]. Moreover, the egress of cells from the bone marrow in this process may be controlled by NE/E [22] and CORTs [21]. However, previous data also show that enhanced myeloid recruitment to the spleen could be caused by minor infections following wounds [23]. Thus, whether or not social stress alone is enough to induce splenomegaly may be debated. Our data did not support any clear stress-induced change in spleen weight.

Stress-induced mononuclear cell migration, proinflammatory activation, and anxiety-like behavior seem to be catecholamine-dependent [25]. Thus, stress may involve activation of the $G$ protein-coupled adrenergic receptors on leukocytes [46]. Furthermore, earlier findings suggest that NE and/or E activation of ADRB2s may induce the expression of pro-inflammatory cytokines through ERK1/2 and MAPK-dependent mechanisms [27]. In addition to $G$ proteins, cytoplasmic adaptor molecules such as ARRB2 may interact with the ADRB2, conveying signals of anti-inflammatory origin by inhibiting NF-кB nuclear translocation [29]. However, PKAand cAMP-dependent suppression of NF- $\mathrm{kB}$ can also be induced by ADRB2 signaling.

Interestingly, our data demonstrated reduced ADRB2 and ARRB2 mRNA levels accompanied by increased mRNA levels of IL-6 in the isolated splenic myeloid cells of the stress-exposed rats. It seems plausible that repeated or persistent NE exposure may cause ADRB2 desensitization [47], which is associated with downregulation of ARRB2 [48]. Reduced levels of ARRB2 may result in increased nuclear translocation and transcriptional activity of NF- $\mathrm{kB}$. Since NF- $\mathrm{kB}$ may bind to the IL-6 promoter [49] for review see [50], it seems reasonable to believe that the expression of IL- 6 is controlled by the transcription factor NF- $\mathrm{kB}$ through a promoter binding mechanism $[51,52]$. It is tempting to speculate that stress-induced upregulation of IL-6 is a result of reduced ARRB2.
The functional diversity of IL-6 may be reflected through its activation of glycoprotein 130 (gp130) and STAT [53] signal transduction. The ubiquitous expression of gp130 allows for a wide range of actions for the cytokines that utilize this pathway [54]. Signal transduction via gp130 has the capacity to suppress innate immune responses [55] and promote adaptive immunity by lymphocyte trafficking [56]. IL-6 is a key mediator in $\mathrm{T}$ cell infiltration of tissue and in the neutrophil to mononuclear cell switch in leukocyte recruitment pattern [57, 58]. Moreover, previous data show that this cytokine is essential for differentiation of naïve $\mathrm{T}$ cells and $\mathrm{B}$ cells into effector cells [59-61]. In addition, IL-6 production and secretion from splenic myeloid cells may act in an autocrine fashion [53]. Thus, stress-induced splenic upregulation of IL- 6 and IL- 6 downstream processes may be important for the transition from the acute to persistent immune activation.

\section{Conclusion}

Taken together, our results suggest that the experience of 1 week of repeated social defeat in rats is a potent stressor that triggers prolonged myeloid inflammatory changes in lymphoid tissues such as the spleen. We believe our results demonstrate neuroendocrine and immunological changes caused by social stress only, not confounding factors such as physical injuries and infections often seen in mice. This shows that the inflammatory effect of such social stress may be stronger than previously assumed. The role of this mechanism following exposure to social stress in humans remains to be investigated.

\section{Supplementary information}

Supplementary information accompanies this paper at https://doi. org/10.1186/s12868-020-00574-4.

Additional file 1: Figure S1. The test used to assess behavior. Figure S2. Plasma. Figure S3. Gating strategy to assess purity of enriched myeloid cell population from rat spleen. Figure S4. Myeloid cells from the spleen. Table S1. Two separate mixes of fluorochrome-conjugated monoclonal antibodies for test and control. The two mixes were separately added to a small fraction of the final cell suspension.

\section{Abbreviations \\ ADRB2: $\beta 2$-adrenergic receptor; ARRB2: $\beta$-arrestin-2; CORT: Corticosterone; $\mathrm{CRH}$ : Corticotropin-releasing hormone; E: Epinephrine; ERK: Extracellular sig- nal-regulated kinases; GC: Glucocorticoid; GM-CSF: Granulocyte-macrophage colony-stimulating factor; HPA: Hypothalamic-pituitary-adrenal; IL-6: Inter-

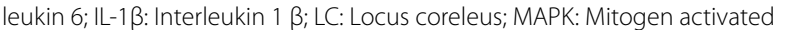 protein kinase; MCP-1: Monocyte chemoattractant protein-1; NE: Noradrena- line; NFKB: Nuclear factor kappa-lit-chain-enhancer of activated B cells; NR3C1: Nuclear receptor subfamily 3, group c, member 1; PFC: Prefrontal cortex; POMC: Pro-opiomelanocortin; PVN: Paraventricular nucleus; SNS: Sympathetic nervous system; STAT: Signal transducer and activator of transcription.}

\section{Acknowledgements}

We thank Anne-Mari Gjestvang Moe, Tiril Schjølberg, Fang-Chin Lin, Oda Helgesen Ramberg and Rune Asgeir Madsen for their excellent technical 
support. We also thank Marianne Bergh and Jannike Mørch Andersen at the Norwegian Institute of Public Health (NIPH) for the NE and CORT concentration measurements.

\section{Authors' contributions}

There are no sources in the current document. DR, IN, DJ, ME, ED, MN, SE, and JG designed the research; DR, IN, DJ and JG performed the research; DR, IN, and JG analyzed the data; DR, IN and JG wrote the paper. All authors read and approved the final manuscript.

\section{Funding}

The study is part of two larger research projects entitled "Workplace bullying: From mechanisms and moderators to problem treatment" funded by The Norwegian Research Council and the University of Bergen/"Psychosocial work factors, persistent back pain and sickness absenteeism-the role of mental distress and epigenetic changes" funded by The Norwegian Research Council and National Institute of Occupational Health. Grant numbers: 250127/237777. The funder was not a participant in any research experiments or data analysis.

\section{Availability of data and materials}

The datasets supporting the conclusions of this article are included within the article and its additional files.

\section{Ethics approval and consent to participate}

All procedures were approved by the Norwegian Food Safety Authority (application ID: 11671) and performed in conformity with laws and regulations controlling experiments and procedures on live animals in Norway $[62,63]$.

\section{Consent for publication}

Not applicable.

\section{Competing interests}

The authors declare no conflicts of interest.

\section{Author details}

${ }^{1}$ Department of Psychosocial Science, University of Bergen, Bergen, Norway.

${ }^{2}$ National Institute of Occupational Health, Oslo, Norway. ${ }^{3}$ Institute of Basic

Medical Sciences, University of Oslo, Oslo, Norway.

Received: 10 February 2020 Accepted: 20 May 2020

Published online: 29 May 2020

\section{References}

1. Flak JN, Myers B, Solomon MB, McKlveen JM, Krause EG, Herman JP. Role of paraventricular nucleus-projecting norepinephrine/epinephrine neurons in acute and chronic stress. European J Neurosci. 2014;39(11):1903-11.

2. Raone A, Cassanelli A, Scheggi S, Rauggi R, Danielli B, De Montis MG. Hypothalamus-pituitary-adrenal modifications consequent to chronic stress exposure in an experimental model of depression in rats. Neuroscience. 2007:146(4):1734-42.

3. Zhou JJ, Gao Y, Zhang X, Kosten TA, Li DP. Enhanced hypothalamic NMDA receptor activity contributes to hyperactivity of HPA axis in chronic stress in male rats. Endocrinology. 2018;159(3):1537-46.

4. Zelena D, Haller J, Halasz J, Makara GB. Social stress of variable intensity: physiological and behavioral consequences. Brain Res Bull. 1999:48(3):297-302

5. Lowrance SA, lonadi A, McKay E, Douglas X, Johnson JD. Sympathetic nervous system contributes to enhanced corticosterone levels following chronic stress. Psychoneuroendocrinology. 2016;68:163-70.

6. Glaser R, Kiecolt-Glaser JK. Science and society - Stress-induced immune dysfunction: implications for health. Nat Rev Immunol. 2005;5(3):243-51.

7. Powell ND, Sloan EK, Bailey MT, Arevalo JM, Miller GE, Chen E, Kobor MS, Reader BF, Sheridan JF, Cole SW. Social stress up-regulates inflammatory gene expression in the leukocyte transcriptome via beta-adrenergic induction of myelopoiesis. Proc Natl Acad Sci USA. 2013;110(41):16574-9.

8. Quan N, Avitsur R, Stark JL, He L, Shah M, Caligiuri M, Padgett DA, Marucha PT, Sheridan JF. Social stress increases the susceptibility to endotoxic shock. J Neuroimmunol. 2001;115(1-2):36-45.
9. Miller GE, Chen E, Sze J, Marin T, Arevalo JM, Doll R, Ma R, Cole SW. A functional genomic fingerprint of chronic stress in humans: blunted glucocorticoid and increased NF-kappa B signaling. Biol Psychiat. 2008;64(4):266-72.

10. Wohleb ES, McKim DB, Shea DT, Powell ND, Tarr AJ, Sheridan JF, Godbout JP. Re-establishment of anxiety in stress-sensitized mice is caused by monocyte trafficking from the spleen to the brain. Biol Psychiatr. 2014;75(12):970-81.

11. Jacobsen DP, Eriksen MB, Rajalingam D, Nymoen I, Nielsen MB, Einarsen S, Gjerstad J. Exposure to workplace bullying, microRNAs and pain; evidence of a moderating effect of miR-30c rs928508 and miR-223 rs3848900. Stress. 2019;23(1):77-86.

12. Cano G, Sved AF, Rinaman L, Rabin BS, Card JP. Characterization of the central nervous system innervation of the rat spleen using viral transneuronal tracing. J Comp Neurol. 2001;439(1):1-18.

13. Kesse WK, Parker TL, Coupland RE. The innervation of the adrenal gland. I. The source of pre- and postganglionic nerve fibres to the rat adrenal gland. J Anatomy. 1988;157:33-41.

14. Badder EM, Santen R, Samojlik E, Harrison TS. Adrenal medullary epinephrine secretion: effects of cortisol alone and combined with aminoglutethimide. J Lab Clin Med. 1980;96(5):815-21.

15. Nezu M, Miura Y, Adachi M, Adachi M, Kimura S, Toriyabe S, Ishizuka Y, Ohashi H, Sugawara T, Takahashi $M$, et al. The effects of epinephrine on norepinephrine release in essential hypertension. Hypertension. 1985;7(2):187-95.

16. Wamsteeker Cusulin Jl, Fuzesi T, Watts AG, Bains JS. Characterization of corticotropin-releasing hormone neurons in the paraventricular nucleus of the hypothalamus of Crh-IRES-Cre mutant mice. PLoS ONE. 2013:8(5):e64943.

17. Osterlund CD, Rodriguez-Santiago M, Woodruff ER, Newsom RJ, Chadayammuri AP, Spencer RL. Glucocorticoid fast feedback inhibition of stress-induced ACTH secretion in the male rat: rate independence and stress-state resistance. Endocrinology. 2016;157(7):2785-98.

18. Felten DL, Felten SY, Carlson SL, Olschowka JA, Livnat S. Noradrenergic and peptidergic innervation of lymphoid tissue. J Immunol. 1985;135(2 Suppl):755s-65s

19. Bierhaus A, Wolf J, Andrassy M, Rohleder N, Humpert PM, Petrov D, Ferstl $R$, von Eynatten $M$, Wendt $T$, Rudofsky $G$, et al. A mechanism converting psychosocial stress into mononuclear cell activation. Proc Natl Acad Sci USA. 2003;100(4):1920-5.

20. Grisanti LA, Evanson J, Marchus E, Jorissen H, Woster AP, DeKrey W, Sauter ER, Combs CK, Porter JE. Pro-inflammatory responses in human monocytes are beta1-adrenergic receptor subtype dependent. Mol Immunol. 2010;47(6):1244-54.

21. Dhabhar FS, Miller AH, McEwen BS, Spencer RL. Stress-induced changes in blood leukocyte distribution role of adrenal steroid hormones. J Immunol. 1996:157(4):1638-44.

22. Engler H, Dawils L, Hoves S, Kurth S, Stevenson JR, Schauenstein K, Stefanski V. Effects of social stress on blood leukocyte distribution: the role of alpha- and beta-adrenergic mechanisms. J Neuroimmunol. 2004;156(1-2):153-62.

23. Engler H, Bailey MT, Engler A, Sheridan JF. Effects of repeated social stress on leukocyte distribution in bone marrow, peripheral blood and spleen. J Neuroimmunol. 2004;148(1-2):106-15.

24. Wohleb ES, Hanke ML, Corona AW, Powell ND, Stiner LM, Bailey MT, Nelson RJ, Godbout JP, Sheridan JF. beta-Adrenergic receptor antagonism prevents anxiety-like behavior and microglial reactivity induced by repeated social defeat. J Neurosci. 2011;31(17):6277-88.

25. Hanke ML, Powell ND, Stiner LM, Bailey MT, Sheridan JF. Beta adrenergic blockade decreases the immunomodulatory effects of social disruption stress. Brain Behav Immun. 2012;26(7):1150-9.

26. Turney $T H$, Harmsen AG. Splenomegaly and other hematological parameters in the socially dominant mouse. Physiol Behav. 1984;33(4):559-62.

27. Powell ND, Bailey MT, Mays JW, Stiner-Jones LM, Hanke ML, Padgett DA, Sheridan JF. Repeated social defeat activates dendritic cells and enhances Toll-like receptor dependent cytokine secretion. Brain Behav Immun. 2009;23(2):225-31.

28. Gao H, Sun Y, Wu Y, Luan B, Wang Y, Qu B, Pei G. Identification of betaarrestin2 as a $G$ protein-coupled receptor-stimulated regulator of NFkappaB pathways. Mol Cell. 2004;14(3):303-17. 
29. Luan B, Zhang Z, Wu Y, Kang J, Pei G. Beta-arrestin2 functions as a phosphorylation-regulated suppressor of UV-induced NF-kappaB activation. EMBO J. 2005;24(24):4237-46.

30. Kaidanovich-Beilin O, Lipina T, Vukobradovic I, Roder J, Woodgett JR Assessment of social interaction behaviors. J Vis Exp. 2011;48:2473.

31. Bergh MS, Bogen IL, Andersen JM, Oiestad AML, Berg T. Determination of adrenaline, noradrenaline and corticosterone in rodent blood by ion pair reversed phase UHPLC-MS/MS. J Chromatogr B Anal Technol Biomed Life Sci. 2018;1072:161-72

32. Iniguez SD, Riggs LM, Nieto SJ, Dayrit G, Zamora NN, Shawhan KL, Cruz $B$, Warren BL. Social defeat stress induces a depression-like phenotype in adolescent male c57BL/6 mice. Stress. 2014;17(3):247-55.

33. Faldt J, Wernstedt I, Fitzgerald SM, Wallenius K, Bergstrom G, Jansson JO. Reduced exercise endurance in interleukin-6-deficient mice. Endocrinology. 2004;145(6):2680-6.

34. Landgraf D, Long J, Der-Avakian A, Streets M, Welsh DK. Dissociation of learned helplessness and fear conditioning in mice: a mouse model of depression. PLoS ONE. 2015;10(4):e0125892.

35. Palminteri S, Justo D, Jauffret C, Pavlicek B, Dauta A, Delmaire C, Czernecki V, Karachi C, Capelle L, Durr A, et al. Critical roles for anterior insula and dorsal striatum in punishment-based avoidance learning. Neuron. 2012;76(5):998-1009.

36. Paulus MP, Rogalsky C, Simmons A, Feinstein JS, Stein MB. Increased activation in the right insula during risk-taking decision making is related to harm avoidance and neuroticism. Neurolmage. 2003;19(4):1439-48.

37. Tsai Cabal A, loanas HI, Seifritz E, Saab BJ. Selective amotivation deficits following chronic psychosocial stress in mice. Behav Brain Res. 2017;317:424-33.

38. Stark JL, Avitsur R, Padgett DA, Campbell KA, Beck FM, Sheridan JF. Social stress induces glucocorticoid resistance in macrophages. Am J Physiol Regul Integr Comp Physiol. 2001;280(6):R1799-805.

39. Patel D, Anilkumar S, Chattarji S, Buwalda B. Repeated social stress leads to contrasting patterns of structural plasticity in the amygdala and hippocampus. Behav Brain Res. 2018;347:314-24.

40. McKim DB, Niraula A, Tarr AJ, Wohleb ES, Sheridan JF, Godbout JP. Neuroinflammatory dynamics underlie memory impairments after repeated social defeat. J Neurosci. 2016;36(9):2590-604.

41. Mouri A, Ukai M, Uchida M, Hasegawa S, Taniguchi M, Ito T, Hida H, Yoshimi A, Yamada K, Kunimoto S, et al. Juvenile social defeat stress exposure persistently impairs social behaviors and neurogenesis. Neuropharmacology. 2018;133:23-37.

42. Vyas A, Pillai AG, Chattarji S. Recovery after chronic stress fails to reverse amygdaloid neuronal hypertrophy and enhanced anxiety-like behavior. Neuroscience. 2004;128(4):667-73.

43. Conrad CD, LeDoux JE, Magarinos AM, McEwen BS. Repeated restraint stress facilitates fear conditioning independently of causing hippocampal CA3 dendritic atrophy. Behav Neurosci. 1999;113(5):902-13.

44. Goldstein LE, Rasmusson AM, Bunney BS, Roth RH. Role of the amygdala in the coordination of behavioral, neuroendocrine, and prefrontal cortical monoamine responses to psychological stress in the rat. J Neurosci. 1996;16(15):4787-98.

45. Vyas A, Mitra R, Shankaranarayana Rao BS, Chattarji S. Chronic stress induces contrasting patterns of dendritic remodeling in hippocampal and amygdaloid neurons. J Neurosci. 2002;22(15):6810-8.

46. Saygin D, Wanner N, Rose JA, Naga Prasad SV, Tang WHW, Erzurum S, Asosingh K. Relative quantification of beta-adrenergic receptor in peripheral blood cells using flow cytometry. Cyto Part A J Int Soc Anal Cytol. 2018;93(5):563-70.

47. Hadcock JR, Malbon CC. Down-regulation of beta-adrenergic receptors: agonist-induced reduction in receptor mRNA levels. Proc Natl Acad Sci USA. 1988;85(14):5021-5.
48. Kizaki T, Izawa T, Sakurai T, Haga S, Taniguchi N, Tajiri H, Watanabe K, Day NK, Toba K, Ohno H. Beta2-adrenergic receptor regulates Toll-like receptor-4-induced nuclear factor-kappaB activation through beta-arrestin 2. Immunology. 2008;124(3):348-56.

49. Xiao W, Hodge DR, Wang L, Yang X, Zhang X, Farrar WL. NF-kappaB activates IL-6 expression through cooperation with c-Jun and IL6-AP1 site, but is independent of its IL6-NFkappaB regulatory site in autocrine human multiple myeloma cells. Cancer Biol Ther. 2004;3(10):1007-17.

50. Luo Y, Zheng SG. Hall of fame among pro-inflammatory cytokines: interleukin-6 gene and its transcriptional regulation mechanisms. Front Immunol. 2016;7:604.

51. Libermann TA, Baltimore D. Activation of interleukin- 6 gene expression through the NF-kappa B transcription factor. Mol Cell Biol. 1990;10(5):2327-34

52. Schwaninger M, Sallmann S, Petersen N, Schneider A, Prinz S, Libermann TA, Spranger M. Bradykinin induces interleukin-6 expression in astrocytes through activation of nuclear factor-kappaB. J Neurochem. 1999;73(4):1461-6.

53. Fu X-L, Duan W, Su C-Y, Mao F-Y, Lv Y-P, Teng Y-S, Yu P-W, Zhuang Y, Zhao $Y$-L. Interleukin 6 induces M2 macrophage differentiation by STAT3 activation that correlates with gastric cancer progression. Cancer Immunol Immunother. 2017;66(12):1597-608.

54. McLoughlin RM, Jenkins BJ, Grail D, Williams AS, Fielding CA, Parker CR, Ernst M, Topley N, Jones SA. IL-6 trans-signaling via STAT3 directs T cell infiltration in acute inflammation. Proc Natl Acad Sci USA. 2005;102(27):9589-94.

55. Xing Z, Gauldie J, Cox G, Baumann H, Jordana M, Lei XF, Achong MK. IL-6 is an antiinflammatory cytokine required for controlling local or systemic acute inflammatory responses. J Clin Investig. 1998;101(2):311-20.

56. Chen Q, Wang WC, Bruce R, Li H, Schleider DM, Mulbury MJ, Bain MD, Wallace PK, Baumann H, Evans SS. Central role of IL-6 receptor signal-transducing chain gp130 in activation of L-selectin adhesion by fever-range thermal stress. Immunity. 2004;20(1):59-70.

57. Fielding CA, McLoughlin RM, McLeod L, Colmont CS, Najdovska M, Grail D, Ernst M, Jones SA, Topley N, Jenkins BJ. IL-6 regulates neutrophil trafficking during acute inflammation via STAT3. J Immunol. 2008;181(3):2189-95.

58. Hurst SM, Wilkinson TS, McLoughlin RM, Jones S, Horiuchi S, Yamamoto N, Rose-John S, Fuller GM, Topley N, Jones SA. II-6 and its soluble receptor orchestrate a temporal switch in the pattern of leukocyte recruitment seen during acute inflammation. Immunity. 2001;14(6):705-14.

59. Diehl S, Anguita J, Hoffmeyer A, Zapton T, Ihle JN, Fikrig E, Rincon M. Inhibition of Th1 differentiation by IL-6 is mediated by SOCS1. Immunity. 2000;13(6):805-15.

60. Hirano T, Yasukawa K, Harada H, Taga T, Watanabe Y, Matsuda T, Kashiwamura S, Nakajima K, Koyama K, Iwamatsu A, et al. Complementary DNA for a novel human interleukin (BSF-2) that induces B lymphocytes to produce immunoglobulin. Nature. 1986;324(6092):73-6.

61. Yang Y, Ochando J, Yopp A, Bromberg JS, Ding Y. IL-6 plays a unique role in initiating c-Maf expression during early stage of CD4 T cell activation. J Immunol. 2005;174(5):2720-9.

62. Animal Welfare Act In. https://lovdata.no/lov/2009-06-19-97.

63. Regulation on the use of animals in research In. https://lovdata.no/forsk rift/2015-06-18-761.

\section{Publisher's Note}

Springer Nature remains neutral with regard to jurisdictional claims in published maps and institutional affiliations. 